\title{
Comparison of Electrorheological Characteristics Obtained in Two Geometrical Arrangements: Parallel Plates and Concentric Cylinders
}

\author{
Petra Peer $^{1, \text { a) }}$, Petr Filip ${ }^{1, \text { b) }}$, Martin Stenicka ${ }^{2, \text { c) }}$ and Vladimir Pavlinek ${ }^{2, d)}$ \\ ${ }^{1}$ Institute of Hydrodynamics, Acad. Sci. Czech Rep., Pod Patankou 5, 16612 Prague, Czech Republic \\ ${ }^{2}$ Centre of Polymer Systems, University Institute, Tomas Bata University in Zlin, \\ Nad Ovčirnou 3685, 76001 Zlín, Czech Republic \\ ${ }^{a)}$ Corresponding author: peer@ih.cas.cz \\ ${ }^{\text {b) }}$ filip@ih.cas.cz
c) stenicka@ft.utb.cz
d) pavlinek@ft.utb.cz
}

\begin{abstract}
The electrorheological characteristics of suspensions of PANI powders suspended in silicone oil measured by a rotational rheometer Physica MCR 501 (Anton Paar Co.) are compared for two different geometrical arrangements parallel plates and concentric cylinders. The individual differences in the results of the measured parameters are discussed.
\end{abstract}

\section{INTRODUCTION}

The general validity and reproducibility of rheological measurements in various laboratories is neither simple nor obvious in spite of the permanent development of new sophisticated rheometers. There is a coincidence of 'classical' rheological characteristics (such as, e.g., shear viscosity) measured for common classical materials. However, for more complicated characteristics and materials the results are quite often different. This can be documented from the examples of M1 and A1 projects carried out in a considerable number of prominent laboratories round the world (Sridhar [1], Hudson and Jones [2]). The non-coincidence of elongational viscosity is remarkable. As the materials used were identical, it proves that other complementary attributes connected with rheological measurements substantially participate in the proper analysis of the studied materials. Generally, among other things, it is possible to mention the process of the preparation of the measured samples, the adequacy of their volume for an applied geometrical arrangement, the materials of which contact surfaces are made, the stability of rheometers, etc. The same problems concern not only measuring the rheological characteristics of the same material in different laboratories, but also measuring the same material at the same laboratory using different rheometers (Rides et al. [3]) or the same rheometer but with various geometrical arrangements (Modigell and Pape [4]).

The literature describing and analysing this discrepancy is very scarce and does not correspond to the significance of the problem, which is further emphasized with the onset of a new generation of so-called smart materials such as those now appearing in magneto- or electro-rheology.

Electrorheological (ER) fluids quickly and reversibly change their structure under the application of an external electric field. The formation of a chain-like structure occurs due to particle polarisation in the direction of an electric field. A number of studies of this mechanism have been summarized in several review papers (Block and Kelly [5], Jordan and Shaw [6], Block et al. [7], Parthasarathy and Klingenberg [8], See [9], Hao [10,11], Sheng and Wen [12]). Most commercially available rheometers can be equipped with ER cells making full use of the functionality of the host instruments. In principle, these devices differ according to the geometry applied - with either parallel plates or concentric cylinders. 
In the present study, the experimental data (flow characteristics) when the same electro-rheological material and rotational rheometer are used, were compared. The only change was in the applied geometrical arrangements parallel plates or concentric cylinders. As documented below, even in this case it is necessary to be careful in making a unique interpretation of the rheological characterisation of the chosen material.

\section{EXPERIMENTAL}

\section{Material}

An electrorheological suspension was prepared by mixing PANI powder (Sigma Aldrich, USA, base, 50,000 g.mol ${ }^{-1}$ ) with silicone oil (Lukosiol M200, Chemical Works Kolin, Czech Republic) in 5, 10, and 15 wt.\% concentrations. PANI powder was ground, sieved to obtain particle sizes smaller than $45 \mu \mathrm{m}$, and dried at $80^{\circ} \mathrm{C}$ in a vacuum oven to a constant weight. Figure 1 illustrates the morphology and wide distribution of PANI particles using a scanning electron microscope VEGA 3 (Tescan, Czech Republic).

The DC conductivity of PANI base particles pressed into pellets (13 $\mathrm{mm}$ in diameter, $1 \mathrm{~mm}$ in thickness) was determined by a four-point method in a van der Pauw setup (Stejskal and Gilbert [13]). The conductivity of the PANI samples attained $7.72 \times 10^{-9} \mathrm{~S} . \mathrm{cm}^{-1}$.

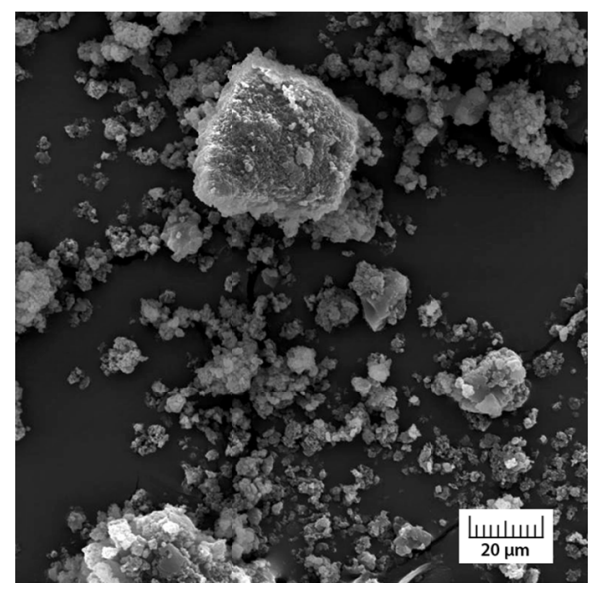

FIGURE 1. SEM pictures of PANI powder.

\section{Device}

A rotational rheometer Physica MCR 501 (Anton Paar Co.) equipped with two ER cells in different geometrical arrangements, parallel plates and concentric cylinders, was employed. The dimensions of the measuring systems used were as follows: P-PTD200/E parallel plates of diameter $50 \mathrm{~mm}$, C-PTD200/E a bob and cup arrangement with the inner and outer diameter $16.6 \mathrm{~mm}$ and $18 \mathrm{~mm}$, respectively. Each geometry was covered with a hood, and the selected temperature (all measurements were carried out at $20^{\circ} \mathrm{C}$ ) was controlled by Peltier elements. The bottom plate for the parallel plate arrangement and the cup in the concentric cylinder geometry were grounded. A spring wire adhering to an upper shaft completed a circuit loop, and opening the hood automatically switched the power supply off. The rheometer itself was fully isolated from an electric current by an insulator inserted in the upper shaft. The intensity of the electric field was varied through an external DC high voltage power supply unit HCP 14-12500 (F.u.G. Elektronik GmbH, Rosenheim, Germany). It provided an electric field strength up to $12.5 \mathrm{kV} . \mathrm{mm}^{-1}$ under the condition that the electric current did not exceed $1 \mathrm{~mA}$ (otherwise voltage was proportionally reduced).

To prevent the vibrations caused by the surrounding influences, the rheometer was accommodated as sketched in Fig. 2. 


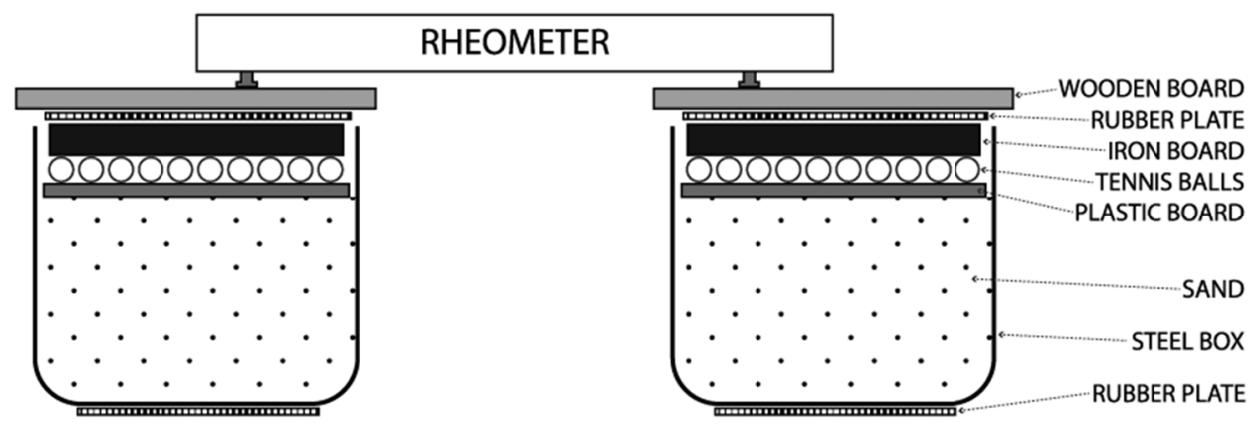

FIGURE 2. Sketch of the rheometer support (each 'leg' consists of a steel box, sieved sand ( $0.6 \approx 0.8 \mathrm{~mm}, 400 \mathrm{~kg})$, plastic board, 70 tennis balls, and iron board $(75 \mathrm{~kg}))$.

\section{RESULTS}

For a more adequate comparison, in all the measurements a gap of $0.7 \mathrm{~mm}$ was held out (for $\mathrm{CC}$ geometry given, for PP geometry adjusted). Prior to the measurements both experimental geometries were calibrated.

Due to the presence of friction between the spring wire and upper shaft, it was first necessary to carry out the measurements merely in air (see Figs. 3 and 4). Then this value had to be subtracted from the data obtained during measurement of a studied material. In the following, all the measured data were processed in this way.
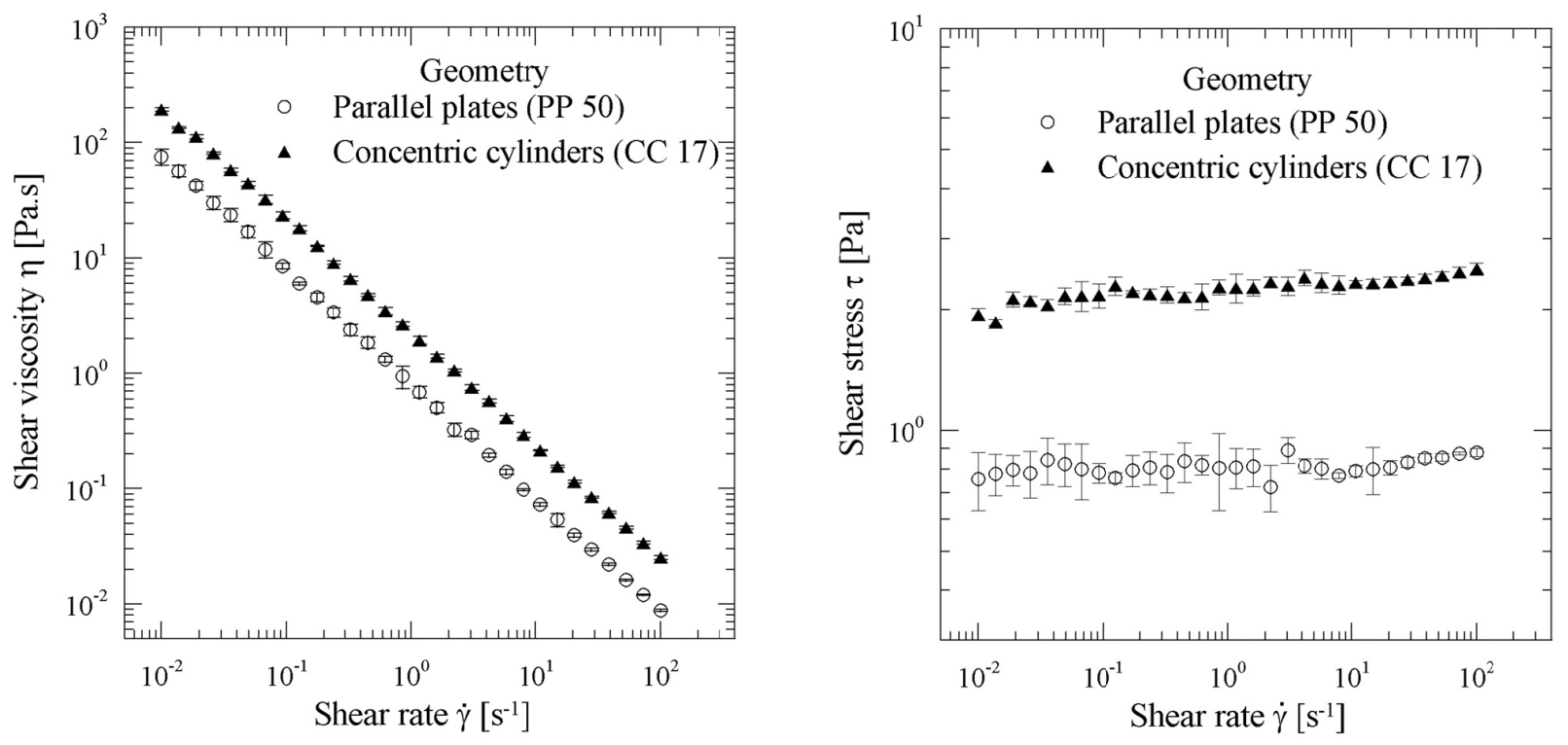

FIGURE 3. Measurement of shear viscosity in different geometries with the 'empty' cell.

\section{Measurements of Silicone Oil with No Electric Field}

A basic introductory comparison of both geometries was carried out with a carrier liquid - silicone oil. This measurement is documented in Fig. 5. Measurements on the top were carried out with a closed hood (with contact between the spring wire and shaft), and at the bottom with an open hood (no contact between the spring wire and shaft). The 'non-homogeneous' influence of the spring wire on the viscosity values for small shear rates was apparent. Therefore, all measurements carried out in the absence of electric field strength were taken with the open hood. As expected, the measurements of the shear viscosity of the Newtonian silicone oil were almost identical in the range $1-100 \mathrm{~s}^{-1}$. 

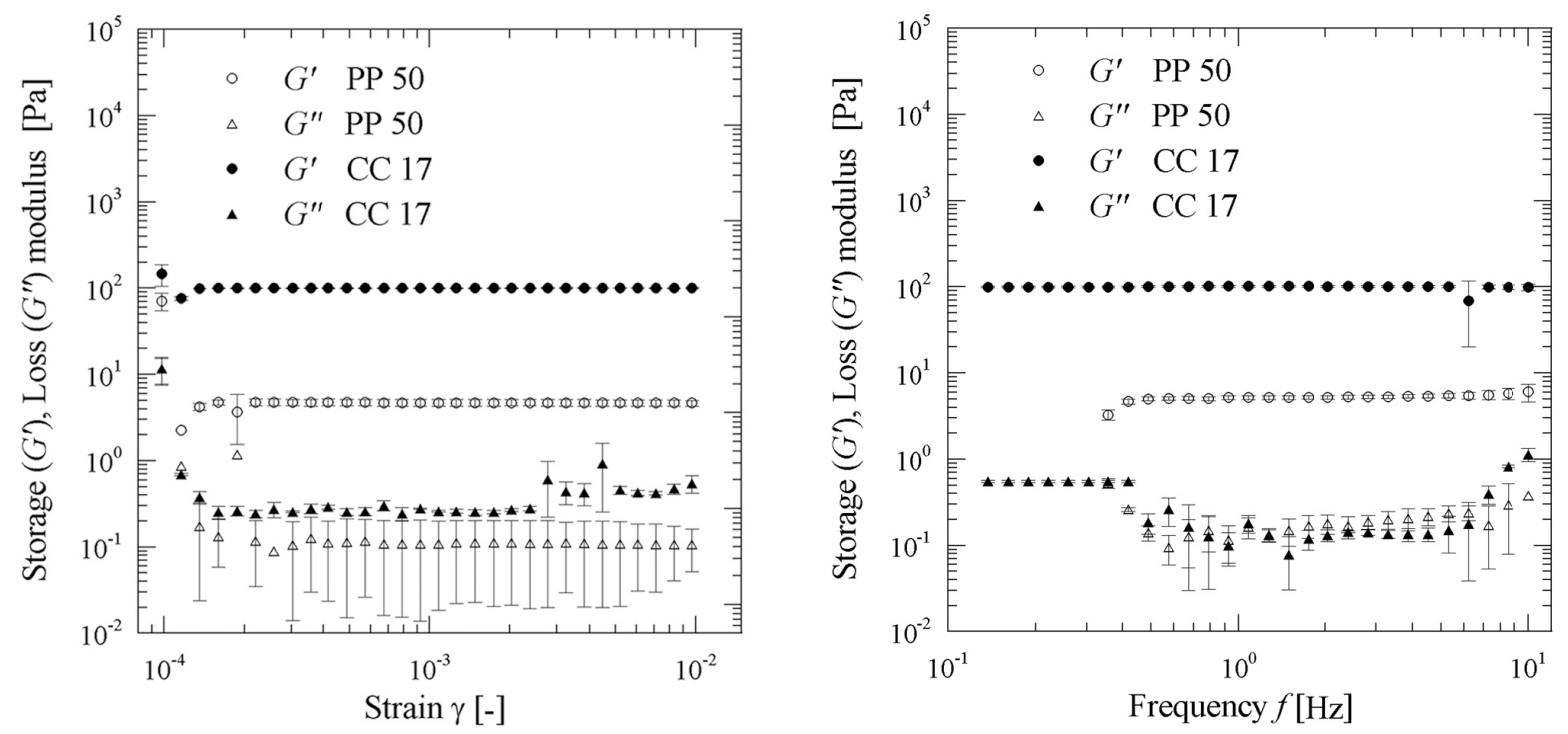

FIGURE 4. Measurement of storage and loss moduli in different geometries with the 'empty' cell.
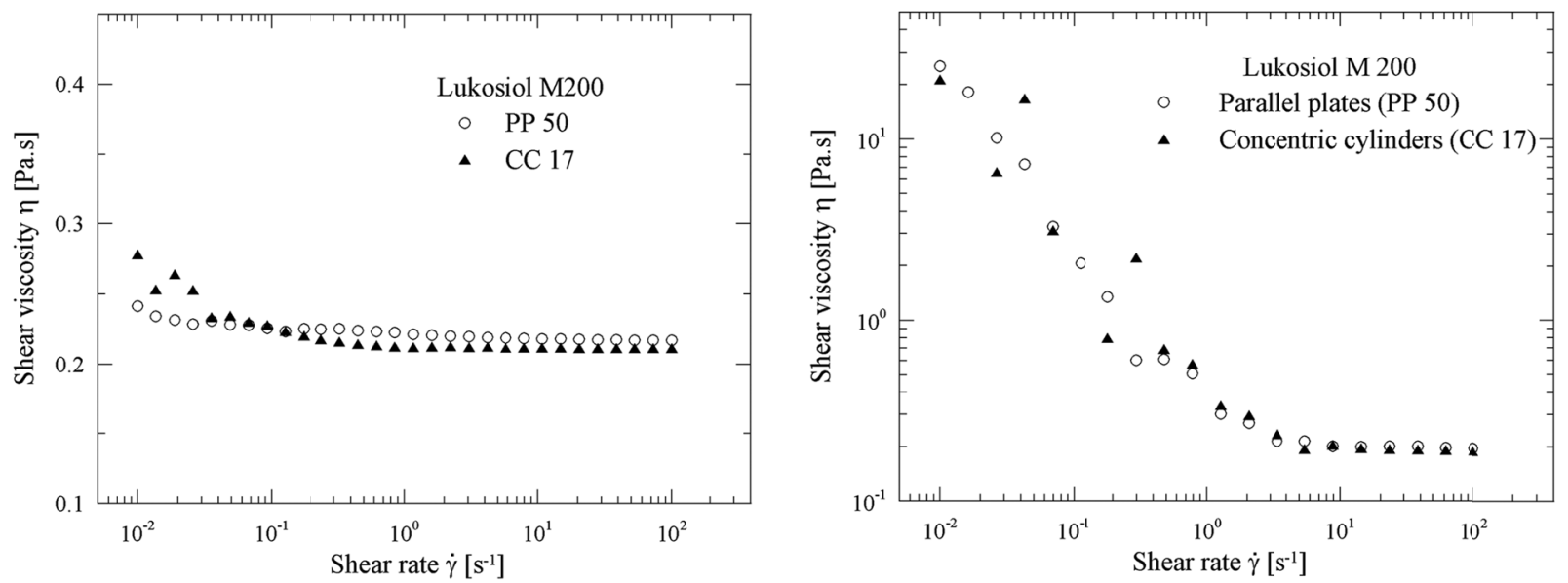

FIGURE 5. Flow curve of the silicone oil $\left(E=0 \mathrm{kV} \cdot \mathrm{mm}^{-1}\right)$, left: open hood, right: closed hood.

TABLE 1. Measurement parameters in individual modes.

\begin{tabular}{|c|c|c|c|c|c|}
\hline & & Mixing & Pause & & Measurement \\
\hline \multirow{4}{*}{$\begin{array}{l}\text { Steady } \\
\text { shear }\end{array}$} & Shear rate & $10 \mathrm{~s}^{-1}$ & $0 \mathrm{~s}^{-1}$ & $0 \mathrm{~s}^{-1}$ & $0.01-100 \mathrm{~s}^{-1}(0 \mathrm{~V})$ \\
\hline & & & & & $0.01-100 \mathrm{~s}^{-1}(\mathrm{xxx} \mathrm{V})$ \\
\hline & Duration & $30 \mathrm{~s}$ & $30 \mathrm{~s}$ & $60 \mathrm{~s}$ & \\
\hline & Voltage & $0 \mathrm{~V}$ & $0 \mathrm{~V}$ & $\mathrm{xxx} V$ & \\
\hline \multirow{5}{*}{$\begin{array}{l}\text { Amplitude } \\
\text { sweep }\end{array}$} & Shear rate & $10 \mathrm{~s}^{-1}$ & $0 \mathrm{~s}^{-1}$ & $0 \mathrm{~s}^{-1}$ & \\
\hline & Strain & & & & $0.0001-0.01[-] / 5 \mathrm{~Hz}(0 \mathrm{~V})$ \\
\hline & & & & & $0.0001-0.01[-] / 3 \mathrm{~Hz}(\mathrm{xxx} \mathrm{V})$ \\
\hline & Duration & $30 \mathrm{~s}$ & $30 \mathrm{~s}$ & $60 \mathrm{~s}$ & \\
\hline & Voltage & $0 \mathrm{~V}$ & $0 \mathrm{~V}$ & $\mathrm{xxx} V$ & \\
\hline \multirow{5}{*}{$\begin{array}{l}\text { Frequency } \\
\text { sweep }\end{array}$} & Shear rate & $10 \mathrm{~s}^{-1}$ & $0 \mathrm{~s}^{-1}$ & $0 \mathrm{~s}^{-1}$ & \\
\hline & Frequency & & & & $0.1-10 \mathrm{~Hz} / 0.001[-](0 \mathrm{~V})$ \\
\hline & & & & & $0.1-10 \mathrm{~Hz} / 0.0006[-](\mathrm{xxx} \mathrm{V})$ \\
\hline & Duration & $30 \mathrm{~s}$ & $30 \mathrm{~s}$ & $60 \mathrm{~s}$ & \\
\hline & Voltage & $0 \mathrm{~V}$ & $0 \mathrm{~V}$ & $x x x V$ & \\
\hline
\end{tabular}




\section{Rheological Measurements of ER Suspensions}

Electrorheological characteristics of the suspension (shear viscosity, storage and loss moduli) were obtained using both ER cells. The samples were stirred mechanically and then placed in an ultrasonic bath for $30 \mathrm{~s}$ before each measurement. Consequently, comparisons were made for three different modes (steady shear, amplitude sweep, and frequency sweep). The courses of the measurements (time intervals, electric field strength (xxx V stands for the individual values of voltage as indicated in the figures), range of measured points) are summarised in Tab. 1. Each point in the steady shear flow measurements as well as in the small-strain oscillatory tests (dynamic amplitude sweep and frequency sweep) was measured at least three times. The time of measurement was correspondingly prolonged with lower values of the studied characteristics.

For shear mode, Figs. 6-8 compare the behaviour of relative viscosity (ratio of the viscosity of suspension to the viscosity of oil) for both geometries (PP 50 and CC 17) consequently for 5,10 , and $15 \mathrm{wt} . \%$ concentrations of PANI particles. Figure 9 presents a mutual comparison of flow behaviour for the above-stated concentrations at constant shear rate $0.23 \mathrm{~s}^{-1}$. This lower shear rate value was chosen intentionally, as for higher values the studied differences become less significant. The comparison concerning the dependence of viscoelastic moduli on strain and angular frequency for both geometries is presented for $10 \mathrm{wt} . \%$ concentration in Figs. 10 and 11. The flow behaviour of suspensions with 5 and $15 \mathrm{wt} . \%$ concentration is analogous.

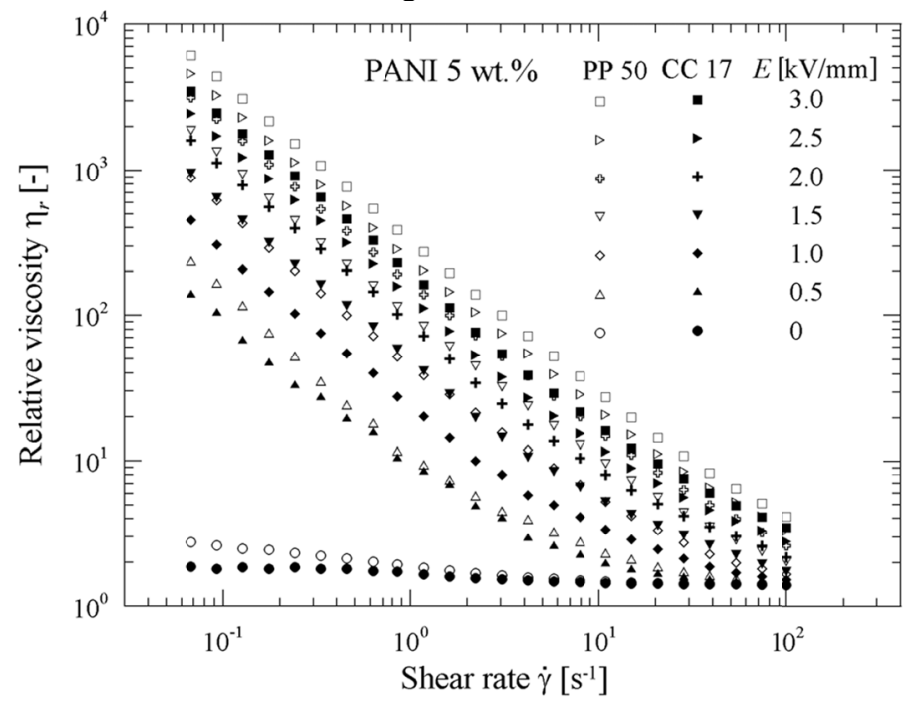

FIGURE 6. Relative viscosity in dependence on shear rate of PANI suspension ( 5 wt.\% concentration).

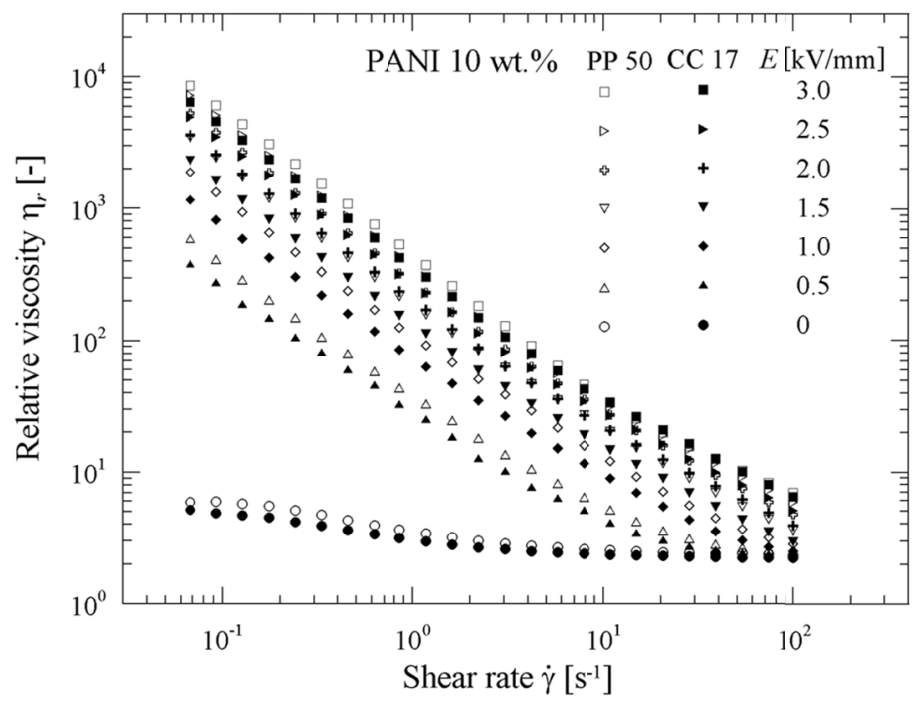

FIGURE 7. Relative viscosity in dependence on shear rate of PANI suspension (10 wt.\% concentration). 


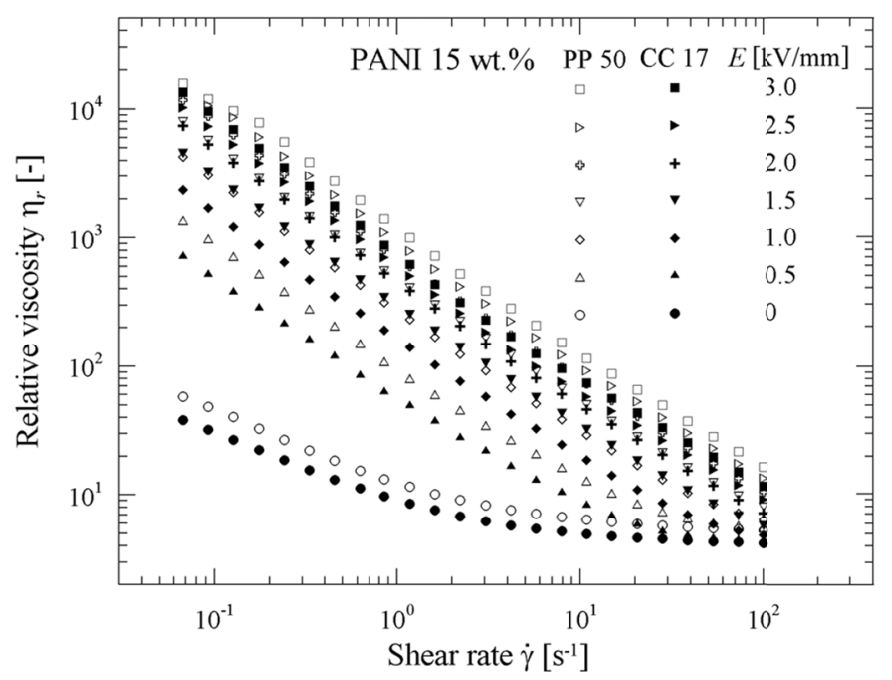

FIGURE 8. Relative viscosity in dependence on shear rate of PANI suspension ( $15 \mathrm{wt} \%$ concentration).

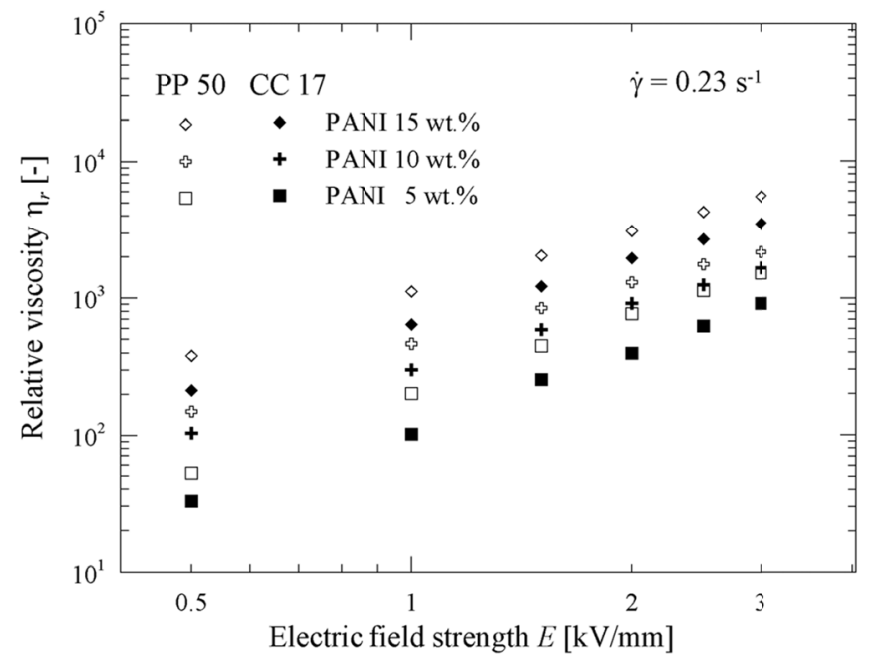

FIGURE 9. Flow behaviour of different concentrations of PANI powder in silicone oil in dependence on electric field strength at fixed shear rate $\left(0.23 \mathrm{~s}^{-1}\right)$.

\section{DISCUSSION}

The experimental data obtained for the two geometrical arrangements exhibit some degree of non-coincidence. This fact is not surprising: cf. e.g. Rides et al. [3], who compared shear viscosity results obtained at high shear rates using extrusion rheometers (the same manufacturer) including an instrumented injection moulding machine.

There is a series of reasons for this deviation:

- different generation of flow;

- different flow conditions for suspended particles;

- difference in contact surface;

- more complicated (trimming) placement of suspension into parallel plate geometry;

- anti-shock balancing in the laboratory (significant for lower values of independent variables);

- different generation of an electric field (radial vs. plan-parallel, see Fig. 12);

- possible appearance of wall slip (Modigell and Pape [4], Barnes [14]) (+ different manifestation in either geometry in combination with possible sedimentation);

- the way of calculating rheological characteristics from raw data generated by either geometry;

- different sedimentation times of ER fluids in different geometries. 

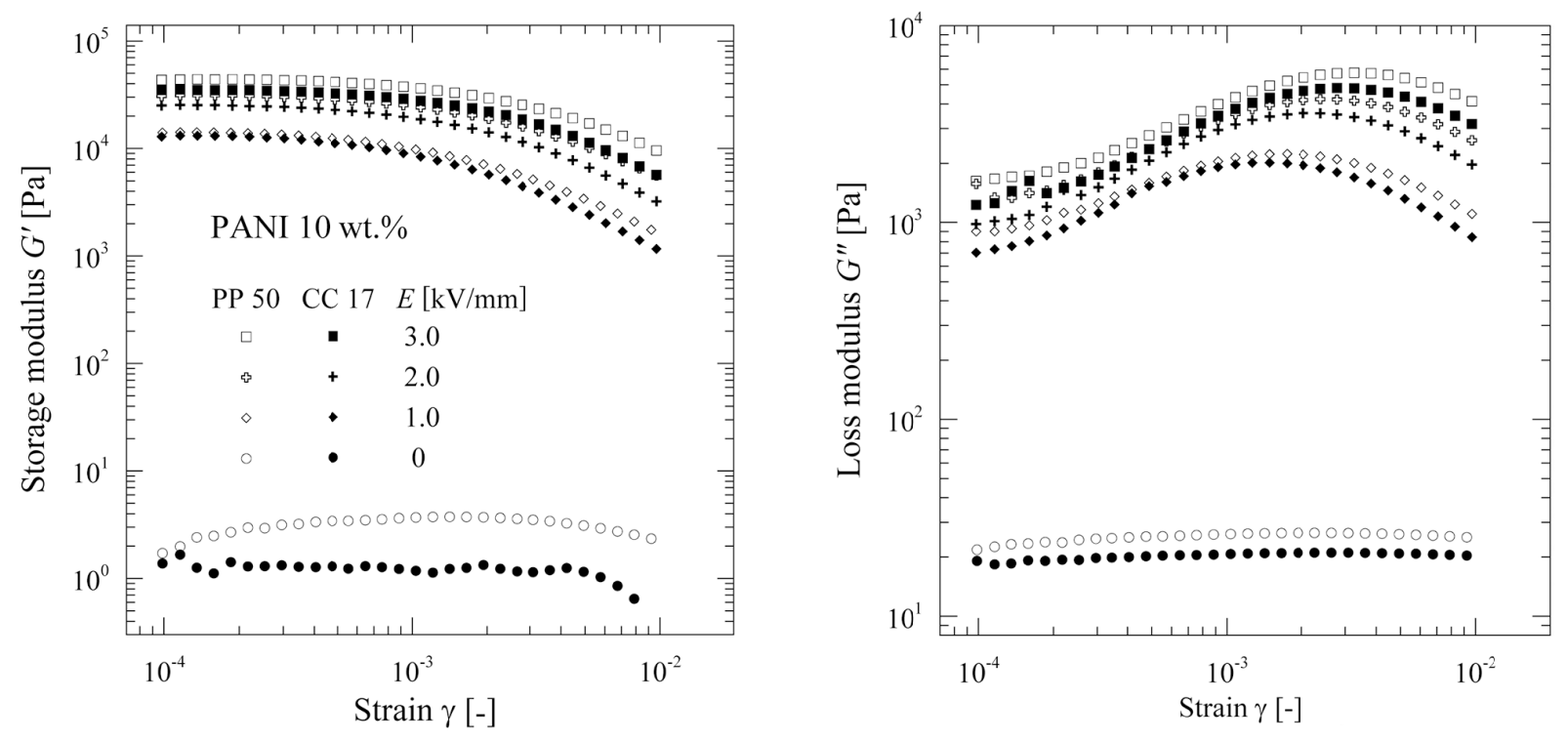

FIGURE 10. Storage and loss moduli in dependence on strain of PANI suspension (10 wt.\% concentration).
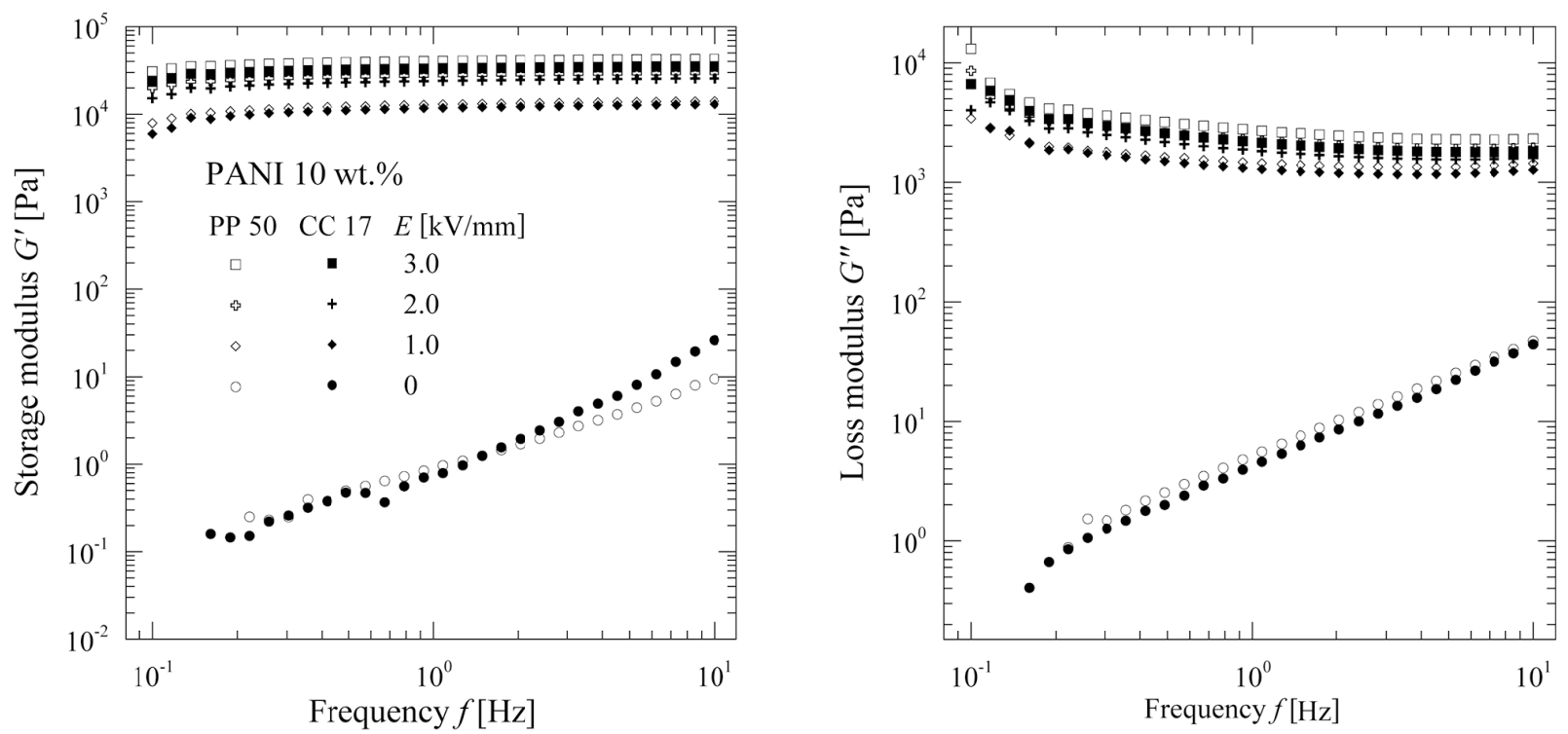

FIGURE 11. Storage and loss moduli in dependence on frequency of PANI suspension (10 wt.\% concentration).

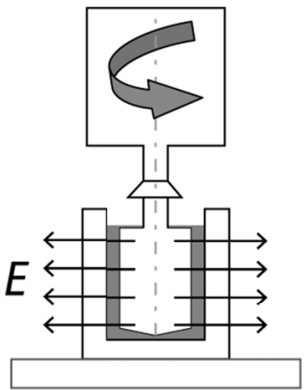

Concentric Cylinders

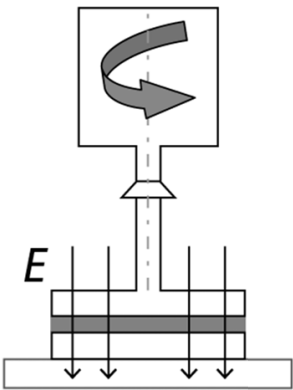

Parallel Plates

FIGURE 12. Radial and plan-parallel orientation of an electric field generated in the individual geometries. 


\section{ACKNOWLEDGMENTS}

The authors wish to acknowledge the RVO: 67985874.

\section{REFERENCES}

1. T. Sridhar, J. Non-Newtonian Fluid Mech. 35, 85-92 (1990).

2. N. E. Hudson and T. E. R. Jones, J. Non-Newtonian Fluid Mech. 46, 69-88 (1993).

3. M. Rides, A. L. Kelly and C. R. G. Allen, Polym. Test. 30, 916-924 (2011).

4. M. Modigell and L. Pape, Solid State Phenomena 141-143, 307-312 (2008).

5. H. Block and J. P. Kelly, J. Phys. D: Appl. Phys. 21, 1661-1667 (1988).

6. T. C. Jordan and M. T. Shaw, IEEE Trans. Electr. Insul. 24, 849-878 (1989).

7. H. Block and J. P. Kelly, A. Qin and T. Watson, Langmuir 6, 6-14 (1990).

8. M. Parthasarathy and D. J. Klingenberg, Mater. Sci. Eng. R 17, 57-103 (1996).

9. H. See, Korea-Austr. Rheol. J. 11, 169-195 (1999).

10. T. Hao, Adv. Mater. 13, 1847-1857 (2001).

11. T. Hao, Adv. Colloid Interface Sci. 97, 1-35 (2002).

12. P. Sheng and W. Wen, Ann. Rev. Fluid Mech. 44, 143-174 (2012).

13. J. Stejskal and R. G. Gilbert, Pure Appl. Chem. 74, 857-867 (2002).

14. H. A. Barnes, J. Non-Newtonian Fluid Mech. 56, 221-251 (1995). 
AIP Conference Proceedings is copyrighted by AIP Publishing LLC (AIP). Reuse of AIP content is subject to the terms at: http://scitation.aip.org/termsconditions. For more information, see http://publishing.aip.org/authors/rights-and-permissions. 